Check for updates

Cite this: RSC Adv., 2017, 7, 44426

Received 8th August 2017

Accepted 7th September 2017

DOI: 10.1039/c7ra08757h

rsc.li/rsc-advances

\section{Folate chitosan conjugated doxorubicin and pyropheophorbide acid nanoparticles (FCDP-NPs) for enhance photodynamic therapy}

Wenting Li, ${ }^{a}$ Guanghui Tan, ${ }^{b}$ Hongyue Zhang, ${ }^{a}$ Zhiqiang Wang ${ }^{* a}$ and Yingxue Jin (D) *a

We prepared new folate chitosan conjugated doxorubicin (DOX) and pyropheophorbide acid (PPa) nanoparticles (FCDP-NPs) using an ionic gelation method with tripolyphosphate (TPP) to enhance photodynamic therapy activity, based on the considerations of the long absorption wavelength $(683 \mathrm{~nm}$ ) of pyropheophorbide acid (PPa) in water and the excellent chemotherapeutic characteristics of doxorubicin (DOX) in cancer therapy. The obtained FCDP-NPs demonstrated a typical spherosome structure, a strong near infrared (NIR) absorption (705 nm) and significantly improved stability and dispersity in PBS $(\mathrm{pH}=5,7,9)$; as well as a high singlet oxygen quantum yield $\left(\Phi_{\Delta}=64 \%\right)$ compared to free PPa $\left(\Phi_{\Delta}=59.1 \%\right)$. In addition, the in vitro cell experiments suggested that FCDP-NPs could be uptaken by HepG2 cells quickly and were mainly located in the cell nucleus. FCDP-NPs showed improved PDT efficiency over pure PPa and DOX at the same concentration after irradiation. Specifically, FCDP-NPs could lead to a $92 \%$ inhibition rate on HepG2 cells at $40 \mu \mathrm{g} \mathrm{mL}^{-1}$ (equal to $6 \mu \mathrm{g} \mathrm{mL}^{-1} \mathrm{DOX}$ ). However, the pure DOX showed little cytotoxicity at $6 \mu \mathrm{g} \mathrm{mL}^{-1}$, which suggests that a small amount of DOX could effectively enhance the PDT activities of PPa and lead to little "dark" cytotoxicity. Moreover, cell morphological changes after PDT treatment further indicated that FCDP-NPs could induce damage and apoptotic cell death efficiently. Finally, the photochemical mechanism of FCDP-NPs during PDT process was investigated by using specific quenching agents sodium azide (SA, a single oxygen quencher) and D-mannitol (DM, a hydroxyl radicals quencher), respectively. The results suggested that Type I and Type II photodynamic reactions can occur simultaneously, yet Type I reaction (the generation of hydroxyl radicals) might play a more important role. All these studies indicated that the FCDP-NPs could be potential nanoparticles in photodynamic cancer treatment.

\section{Introduction}

Photodynamic therapy (PDT) has been a potential therapeutic method for the treatment of various cancers with significant efficacy. ${ }^{1-3}$ Traditional methods such as chemotherapy, radiotherapy and surgery have limitations in clinical treatment. Take the case of chemotherapy, it can successfully kill the cancer cells, yet it can produce systemic toxicity and resistance, severely affecting the physical and mental health of the patients. ${ }^{4,5}$ Owing to the low side effects, special selectivity and being minimally invasive, PDT overcomes the limitations of traditional treatments. PDT relies on selective accumulation of a photosensitizing agent (photosensitizer) in tumor and subsequent photodynamic effect induced by activation of the

${ }^{a}$ Key Laboratory of Photochemistry Biomaterials and Energy Storage Materials of Heilongjiang Province, College of Chemistry \& Chemical Engineering, Harbin Normal University, Harbin, 150025, China. E-mail: jyxprof@163.com; wzq70402@ 163.com; Tel: +86-451-88060569

${ }^{b}$ Key Laboratory of Molecular Cytogenetics and Genetic Breeding of Heilongjiang Province, Harbin, 150025, China photosensitizer by visible light. ${ }^{6,7}$ Photosensitizers can be excited from its ground state to a triplet excited state by a momentary excited singlet state. The formed triplet states either undergo electron or hydrogen atom transfer reactions with a substrate to produce free radicals such as hydroxyl radical, or transfer its energy directly to oxygen to form excited state singlet oxygen. ${ }^{8-10}$ These reaction oxygen species (ROS) have a very strong activity to cause destruction through direct cellular damage and activation of an immune response against cancer cells. ${ }^{\mathbf{1 1}}$ Besides, the photosensitizers can quickly enrichment in the tumour cells, thus PDT can reach a good curative effect on cancer therapy. Therefore, many PSs have been developed for PDT, such as Photofrin, hemoporfin, Chlorin e6 (Ce6). ${ }^{12,13}$ Nevertheless, some of the disadvantages of the photosensitizers (PSs) are not neglected. Most of the photosensitizers possess porphyrin or porphine structures, which have larger hydrophobic groups, and the solubility in water is not ideal. ${ }^{\mathbf{1 4}}$ The larger aromatic conjugate system leads to the molecular accumulation and reduces the yield of reactive oxygen. Moreover, some PSs take longer time to metabolize in the tumour site with the blood circulation; therefore the 
patients should stay in dark for a long period of time. So PDT needs to be studied deeply to overcome the limitation in clinic therapy.

Generally, appropriate drug carrier with good biocompatibility and target ability could reduce or overcome the disadvantages of chemotherapy drugs and photosensitizers. ${ }^{15}$ Such carrier systems could not only control the rate of drug administration that prolongs the duration of the therapeutic effect but also deliver the drug to specific site. ${ }^{16-18}$ Chitosan is a non-toxic biodegradable polycationic polymer with low immunogenicity. ${ }^{19}$ Hydrophilic chitosan nanoparticles have shown favourable biocompatibility characteristics and could improve membrane permeability both in vitro and in vivo, and could be degraded by lysozyme in serum. ${ }^{20}$ Although chitosan nanoparticles are good substrate in drug delivery system, but most of the nanoparticles are ingested by mononuclear phagocytic systems (MPS), it has good effect on the treatment of MPS related diseases, yet it does little for other diseases. ${ }^{21}$ Folic acid (FA) is a kind of vitamin and is appealing as a ligand for targeting cell membrane, allowing nanoparticle endocytosis via the folate receptor (FR). ${ }^{22,23}$ Folate receptor (FR) is a single-chain glycoprotein with high specific affinity for folic acid and methotrexate, and is largely shielded from the immune system in normal tissue but highly expressed on a variety of malignant tumour tissues. ${ }^{24-26}$ More importantly, the high affinity of folic acid to its receptor and the small size allows its use for specific cell targeting. Moreover, the ability of FA to bind its receptor to allow endocytosis is not altered by covalent conjugation of small molecules. Therefore, many researchers have used FA as a ligand with liposome and other polymers for target therapy in many fields. ${ }^{27,28}$ Doxorubicin and its bioactive derivatives are among the most widely used anticancer drugs in chemotherapy treatment. For example, doxorubicin (DOX) used as a prodrug to formulated nanoparticles for NIR-triggered high-efficient photodynamic and chemocascade therapy. ${ }^{29,30}$

Considering the advantages of FA, CS and DOX mentioned above, in this paper, we designed and prepared folate chitosan conjugated doxorubicin and pyropheophorbide acid nanoparticles (FCDP-NPs) to enhance photodynamic therapy of PPa, which is the second generation photosensitizer with large molar extinction coefficient to transfer the energy for sufficient ROS generation, and a larger absorption wavelength $(683 \mathrm{~nm}$, located in therapeutic window) ensuring the deep penetration of light into tissues, being suitable for the photodynamic therapy. In our strategy, we used folic acid as a specific substance for tumor target, chitosan as the matrix of nanoparticles, PPa as a photosensitizer and DOX as a chemotherapy drug to improve the PDT activities. Firstly, folate chitosan was synthesized by dehydration condensation reaction with the use of dicyclohexylcarbodiimide (DCC) and $N$-hydroxysuccinimide (NHS). Secondly, the obtained folate chitosan were blended with doxorubicin (DOX) and pyropheophorbide acid (PPa). Then we got the multifunction nanoparticles (FCDP-NPs) by inotropic gelation methods with tripolyphosphate (TPP). The singlet oxygen yield of FCDP-NPs was then tested by using the 1,3-diphenylisobenzofuran (DPBF) as a detector, and compared with pure $\mathrm{PPa}$ and folate chitosan conjugated pyropheophorbide acid nanoparticles (FCP-NPs) simultaneously. Furthermore, the chemical and photo-stability of FCDP-NPs in phosphate buffered solution $(\mathrm{pH}=5,7,9)$ were investigated to evaluate the potential in PDT. In addition, the in vitro PDT activities, including the cellular uptake experiments, the cell photo-toxicity and dark toxicity experiments were investigated on HepG2 cells, the FCDP-NPs could enter the cells quickly and mainly located in cell nucleus in some degree. Besides, the formation of reactive oxygen species in HepG2 cells after PDT treatment was also studied. All the studies indicated that the small amount of DOX in FCDP-NPs can enhance the photodynamic activities, and the FCDP-NPs can be a great potential candidate in cancer therapy.

\section{Results and discussion}

\subsection{Synthesis of FCDP-NPs}

PPa is a good photosensitizer with large molar extinction coefficient and long absorption wavelength (683 nm in water). Meanwhile, DOX was known as the widely used chemotherapy drug, so we selected PPa as PDT drug and DOX as chemotherapy drug to increase the effective of PDT. The prepared methods were shown in Scheme 1, the folate chitosan (FC) was first
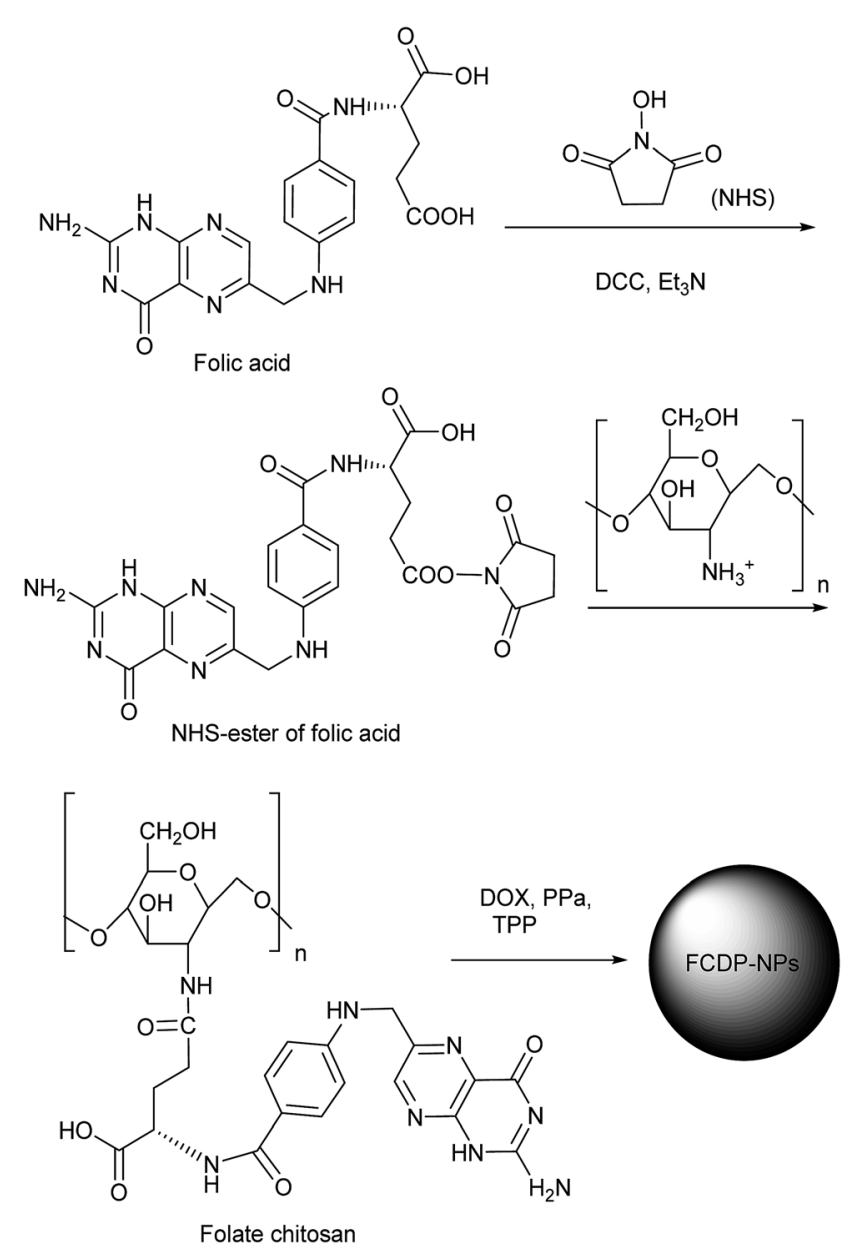

Scheme 1 The preparation of folate chitosan conjugated doxorubicin and pyropheophorbide acid nanoparticles (FCDP-NPs). 
prepared throw dehydration condensation reaction by DCC and NHS using folic acid and chitosan as the starting materials. The FC was purified from unreacted folic acid and chitosan by Sephadex G-10 gel chromatography, using $2 \%$ acetic acid buffer as eluent. Secondly, the obtained FC blended with DOX and PPa under stirring to generate folate chitosan conjugated doxorubicin and pyropheophorbide acid (FCDP), which was transformed into nanoparticles (FCDP-NPs) through tripolyphosphate (TPP) by ionic gelation method. The FCDPNPs were shown good stability under test conditions.

\subsection{Characterization of FCDP-NPs}

Via inotropic gelation methods, the FCDP-NPs were formed successfully, which was comprehensively confirmed by the following characterization analysis.

The folate-chitosan (FC) was prepared through dehydration condensation reaction by DCC and NHS using folic acid and chitosan as the starting materials. The folate chitosan were purified by Sephadex G-10 gel chromatography, during which the fractions with high molecular weight would be eluted firstly followed by the fractions with small molecular weight. Due to that the chitosan has no absorption from 300 to $800 \mathrm{~nm}$, the absorbance of folic acid at $363 \mathrm{~nm}$ was used to monitor the different collected fractions. As shown in Fig. 1a, two distinct
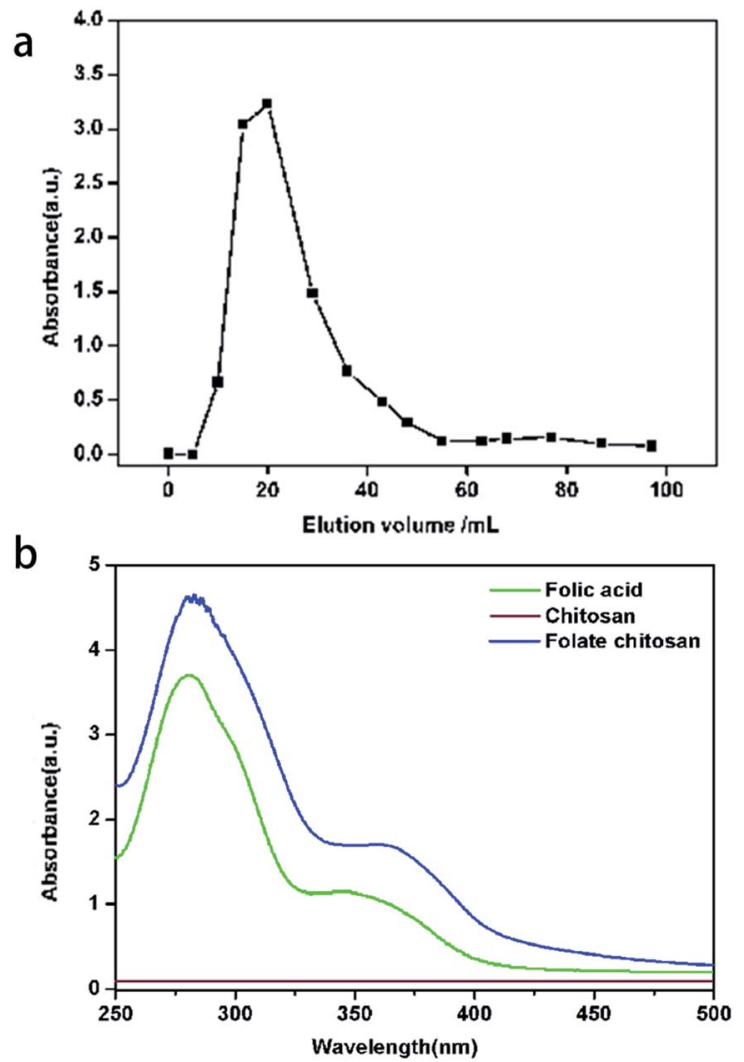

Fig. 1 (a) The Sephadex G-10 gel chromatography of folate chitosan eluted with $2 \%$ acetic acid. The absorbance at $363 \mathrm{~nm}$ was used to monitor the different collected fractions. (b) The UV spectra of folic acid, chitosan and folate chitosan in water solution. peaks were observed and the separation was complete. The first one corresponded to folate chitosan with a high molecular weight and the second one corresponded to the unreacted folic acid with a low molecular weight. ${ }^{31}$ The UV spectra of folic acid, chitosan and folate chitosan were showed in Fig. 1b. The folic acid had two absorption, a weak peak at $363 \mathrm{~nm}$ and a strong at $280 \mathrm{~nm}$, chitosan have no absorption from 300 to $800 \mathrm{~nm}$ and the absorption of folate chitosan was similar to the folic acid. To evaluate the extent of folate conjugation in folate chitosan, the quantitative UV analysis was performed, and it was found that $8.23 \%$ folic acid was linked to chitosan molecules.

In order to clarify the size and morphology of FCDP-NPs, transmission electron microscope (TEM) were adopted. Fig. 2a showed the TEM image of FCDP-NPs, which clearly displayed that the nanoparticles presented a typical spherosome structure with a diameter of $8 \pm 1.23 \mathrm{~nm}$. Meanwhile, the hydrodynamic diameters of FCDP-NPs were measured using dynamic light scattering (DLS) analysis showed in Fig. 2d, and the mean diameters of FCDP-NPs in water was approximately $69.5 \pm$ $4.47 \mathrm{~nm}$, noted that the size of FCDP-NPs characterized by TEM was much smaller than the ones obtained by DLS, which is mainly due to that DLS gives a hydrodynamic size that corresponds to the core and the swollen corona of the micelles, whereas TEM often gives a size of the core for micelles in a dried state as the corona with low electronic density is not visible. Therefore, the nanoparticles size from TEM often stands for the actual size of the nanoparticles. In addition, the functional groups on the surface of the nanoparticles in water solution, such as the hydroxyl group and carboxyl group, will make the nanoparticles absorb together to form a larger agglomeration, which will make DLS more larger than the actual size. Meanwhile, the hydrodynamic sizes of the FCDP-NPs at different storage time periods were also recorded to evaluate their longterm colloidal stability, and the hydrodynamic size does not have any appreciable changes within a time period of $24 \mathrm{~h}$. What's more, the zeta potential of the FCDP-NPs, free chitosanNPs, FCD-NPs (folate chitosan conjugated DOX nanoparticles) and FCP-NPs (folate chitosan conjugated PPa nanoparticles) at pH 7.0 in water were all investigated. As shown in Fig. 2c, the zeta potential of free chitosan-NPs was $12.45 \pm 0.55 \mathrm{mV}$, FCDNPs was $11.19 \pm 0.9 \mathrm{mV}$, FCP-NPs was $4.97 \pm 0.24 \mathrm{mV}$, and FCDP-NPs was $7.43 \pm 0.67 \mathrm{mV}$. Based on the above investigation, it was clear that FCDP-NPs had been successfully synthesized, which was also confirmed by the UV spectra. Fig. 2b displayed the UV spectra of folate chitosan, PPa, DOX and FDCP-NPs. PPa presented the typical absorptions of chlorophyll, that is, a strong absorption soret band at $413 \mathrm{~nm}$ and a shoulder $\mathrm{Q}_{y}(0,0)$ band at $683 \mathrm{~nm}$ in water; the DOX showed a strong absorption at $490 \mathrm{~nm}$, and the folate chitosan showed a strong absorption peaks at $280 \mathrm{~nm}$ and a shoulder peak at $363 \mathrm{~nm}$. The obtained FCDP-NPs exhibits a broader soret peak (415 $\mathrm{nm})$ and $\mathrm{Q}_{y}(0,0)$ bands at $705 \mathrm{~nm}$. It can be easily concluded that the largest absorption wavelength $\mathrm{Q}_{y}(0,0)$ of FCDP-NPs showed significant red-shift from $683 \mathrm{~nm}$ to $705 \mathrm{~nm}$ comparing with PPa, yet it still maintains the normal absorption characteristics of free $\mathrm{PPa}$. 
a

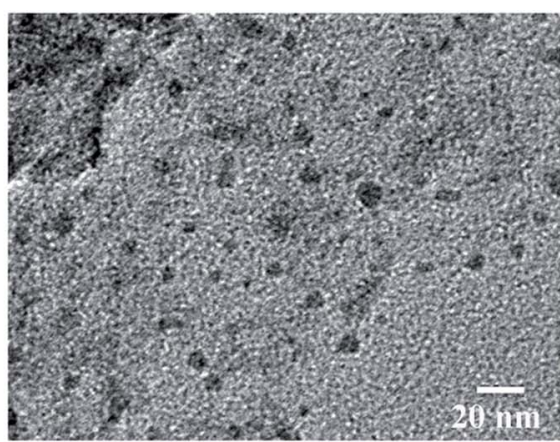

C

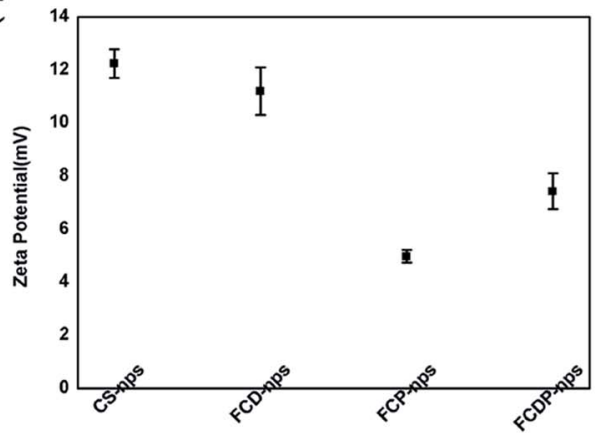

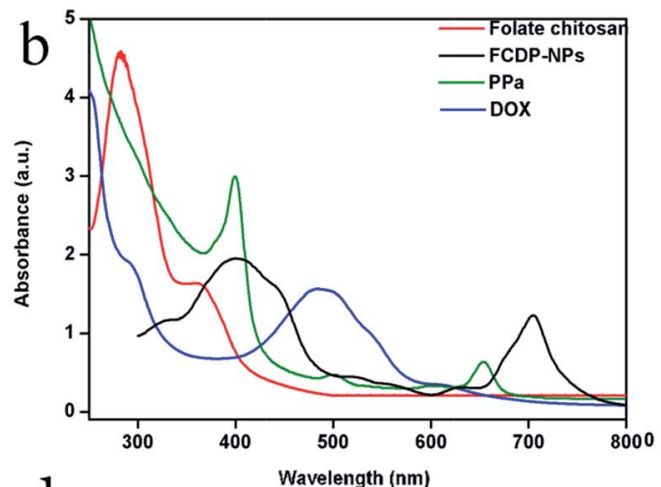

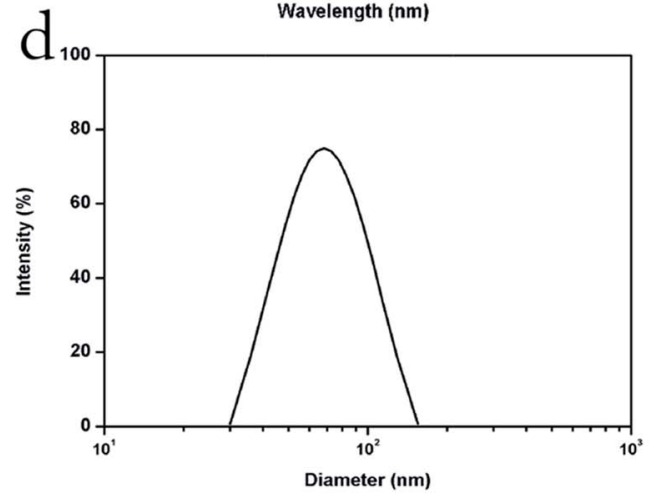

Fig. 2 (a) TEM images of FCDP-NPs (b) the UV spectra of folate chitosan, PPa, DOX and FCDP-NPs in water solution (c) zeta potential of CSNPs, FCD-NPs, FCP-NPs and FCDP-NPs (d) the hydrodynamic size distribution of FCDP-NPs measured by dynamic light scattering (DLS).

The loading capacity (LC) of the nanoparticles was also determined by the change of absorption of the samples before and after encapsulation. Firstly, pure PPa was determined by measuring its $\mathrm{Q}_{y}$ absorbance $(A)$ at $683 \mathrm{~nm}$, the correlation between absorption and the concentrations of PPa was normalized by linear regression, and the standard curve has a well correlation coefficient $\left(R^{2}=0.9976\right)$, described by the following equation: $Y=0.0066 X+0.0812$. Pure DOX was determined by the same methods by measuring its absorbance (A) at $490 \mathrm{~nm}$, and the standard curve also has a well correlation coefficient $\left(R^{2}=0.9984\right)$, described by the following equation: $Y=0.0048 X+0.0771$. According to the formula as describe in the experimental part, the final loading capacity of PPa was $10.24 \pm 0.92 \%$ and DOX was $15.67 \pm 1.2 \%$. The loading capacity was also used to calculate the concentration of PPa and DOX in FCDP-NPs.

Next, we studied the drug release of FCDP-NPs in Dulbecco's Modified Eagle Medium (DMEM). As shown in Fig. 3a, the FCDP-NPs showed a burst release of $45 \%$ at $2 \mathrm{~h}$, followed by an additional release of $36 \%$ over $24 \mathrm{~h}$, indicating that the FCDPNPs could release half of the PPa in a short time, and after $24 \mathrm{~h}$, about $80 \%$ of the PPa could be released from FCDP-NPs. Moreover, the absorption FCDP-NPs at $705 \mathrm{~nm}$ in PBS $(5 \times$ $10^{-4} \mathrm{M}, \mathrm{pH}=5,7,9$, respectively) was measured in evaluate the stability of FCDP-NPs. The results were shown in Fig. 3b-d. It was found that FCDP-NPs was degraded in different $\mathrm{pH}$ conditions, yet after $24 \mathrm{~h}$, the degradation rate of FCDP-NPs in PBS $(\mathrm{pH}=5)$ was higher than that in PBS $(\mathrm{pH}=7)$ and PBS $(\mathrm{pH}=9)$, indicated that FCDP-NPs were more stable in neutral and alkaline environment than acidic environment. Therefore, it is reasonable to believe that FCDP-NPs has better stability in PBS medium and at physiological $\mathrm{pH}$, which could be served as a potential photosensitizer for in vivo photodynamic therapy.

\subsection{Singlet oxygen quantum yield}

Energy transfer between the triplet state of a PS and ground state molecular oxygen leads to the production of singlet oxygen. It is essential to generate large amounts of singlet oxygen. Generally speaking, single oxygen $\left({ }^{1} \mathrm{O}_{2}\right)$ is the mainly reactive agent of photosensitizer induced photodynamic therapy (PDT), and it is necessary for PDT. In order to measure the generation of singlet oxygen, DPBF (1,3-diphenylisobenzofuran), a quencher of singlet oxygen $\left({ }^{1} \mathrm{O}_{2}\right)$ with maximum absorption peak at $415 \mathrm{~nm}$ was used in this experiment. ${ }^{32,33}$ Fig. 4a showed the UV absorption spectra of DPBF after reacting with ${ }^{1} \mathrm{O}_{2}$ produced by FCDP-NPs under different irradiation times $\left(675 \pm 10 \mathrm{~nm}, 10 \mathrm{~J} \mathrm{~cm}^{-2}\right)$. The gradually decreased absorbance with increasing irradiation time indicated that FCDP-NPs could efficiently produce ${ }^{1} \mathrm{O}_{2}$, thus leading to the decomposition of DPBF. Meanwhile, the ${ }^{1} \mathrm{O}_{2}$ quantum yield $\left(\Phi_{\Delta}\right)$ of FCDP-PNs was obtained as $64 \%$ (correlation coefficient $\left.R^{2}>0.9936\right)$ according to the calculation by using methylene blue as the reference compound $\left(\Phi_{\Delta}=49.1 \% \text { in DMF }\right)^{34}$ However, the ${ }^{1} \mathrm{O}_{2}$ quantum yield of pure PPa was $59.1 \%$ and FCP-NPs was $61.2 \%$, there were little lower than that of FCDPNPs. Thus, FCDP-NPs may cause excellent cell toxicity in vitro because of the high generation of singlet oxygen in the experimental conditions. 

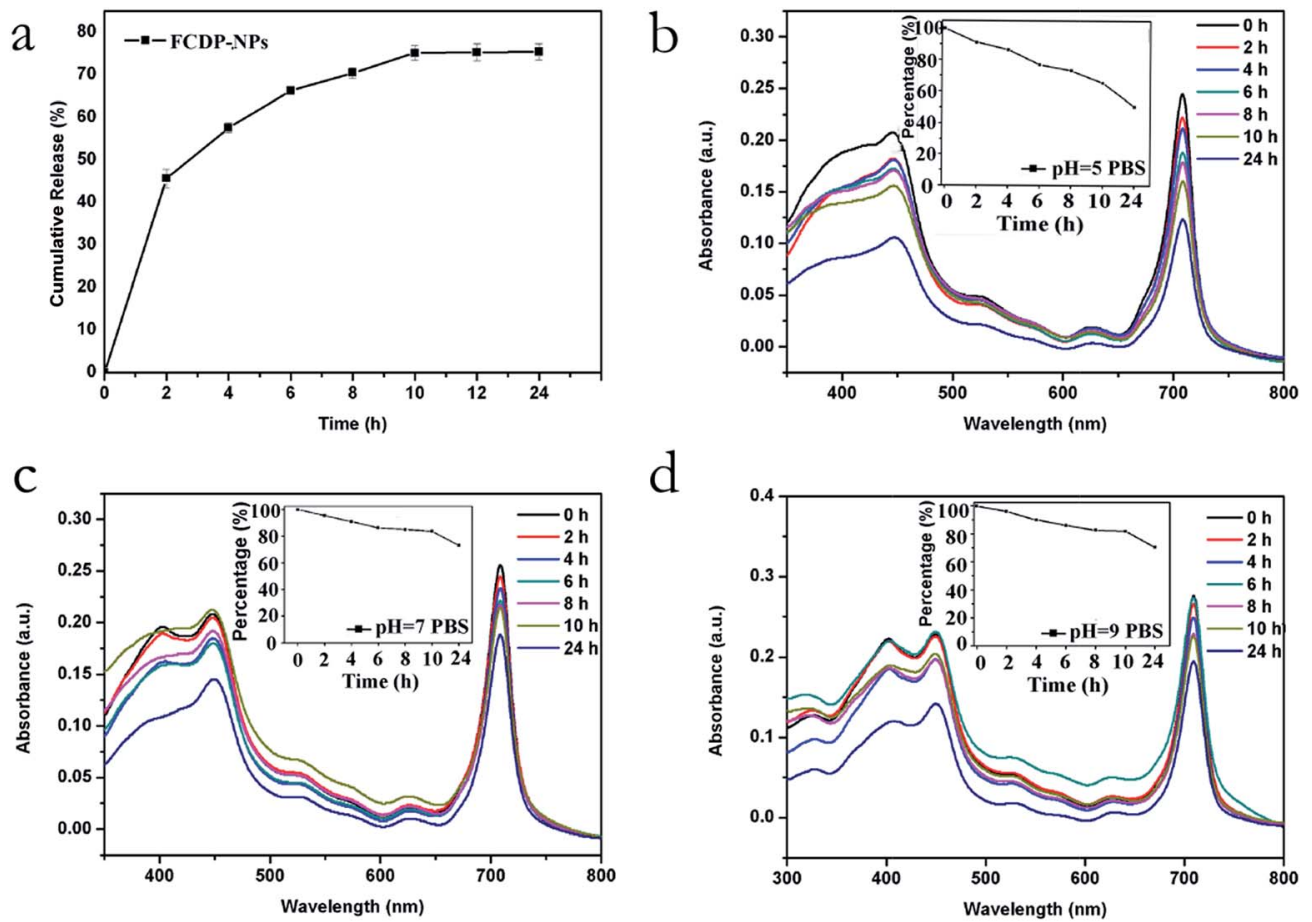

Fig. 3 (a) Release of PPa from FCDP-NPs in DMEM cell culture medium (b) the UV spectra of FCDP-NPs in $\mathrm{pH}=5 \mathrm{PBS}$ at different times. (c) The UV spectra of FCDP-NPs in $\mathrm{pH}=7$ PBS at different times. (d) The UV spectra of FCDP-NPs in $\mathrm{pH}=9$ PBS at different times.

\subsection{Photobleaching}

Photobleaching is an important property of a photosensitizer, and it is often completely or partially coupled to the photodynamic reaction. Excellent anti-photobleaching ability is very important for an ideal PS. Photobleaching is usually considered as a disadvantage because it can reduce the yield of reactive oxygen substance (ROS) and decreases the ability to destroy tumours, so the photostability of a PS is great importance for PDT. In this paper, the absorptions of FCDP-NPs and FCP-NPs in PBS $\left(2 \times 10^{-4} \mathrm{M}\right)$ at $705 \mathrm{~nm}$ were recorded to test the photostability after different irradiation time. The photobleaching curves were drawn according to the absorption at $705 \mathrm{~nm}$ and irradiation time. According to the curve in Fig. 5, despite the slightly decreased absorption of FCDP-NPs and FCP-NPs with increasing time, yet the declining trend was slow. Specially, after irradiation of $10 \mathrm{~min}$, there was only $3 \%$ photobleaching rate for FCDP-NPs. Considering that the PS could achieve good PDT effect after a $10 \mathrm{~min}$ irradiation, the photobleaching of FCDP-NPs has a little influence on PDT effect. Moreover, it is interesting that FCDP-NPs showed lower photobleaching rate than those of FCP-NPs in spite of a not significant different, yet it still suggested that the introduction of DOX would improve the photostability to some extent. We suspect the multicyclic structure of DOX with potential chromophore (multi-
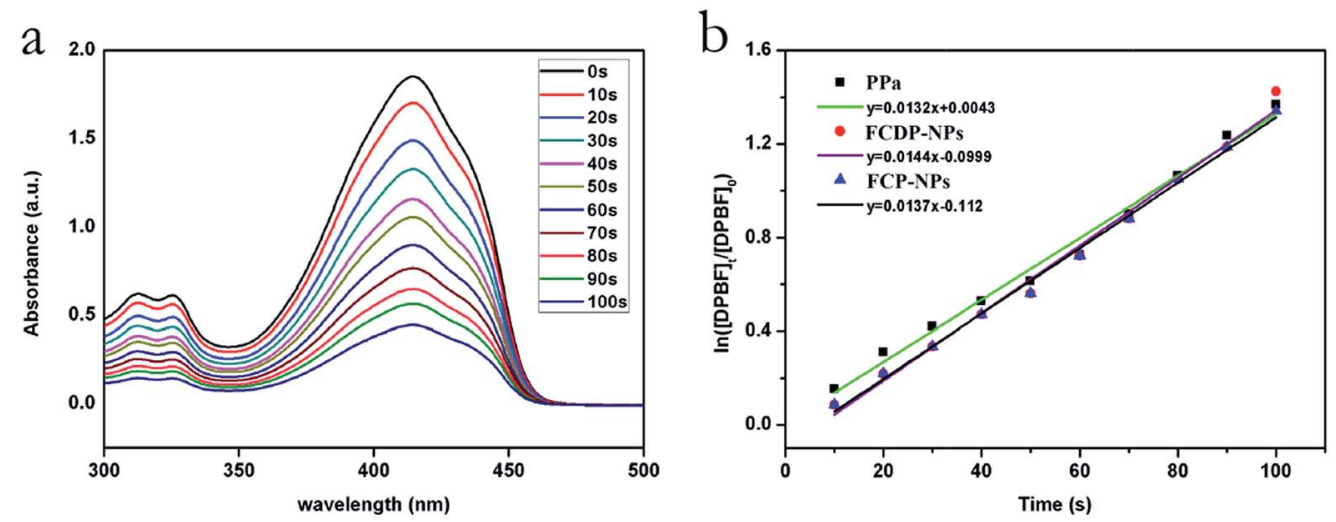

Fig. 4 Ultraviolet-visible absorption spectra (a) of photodecomposition of DPBF by ${ }^{1} \mathrm{O}_{2}$ after irradiation of FCDP-NPs, and first-order plots (b) for the photodecomposition of DPBF photosensitized by PPa, FCP-NPs and FCDP-NPs respectively, monitoring the maximum absorption of DPBF at $415 \mathrm{~nm}$. 


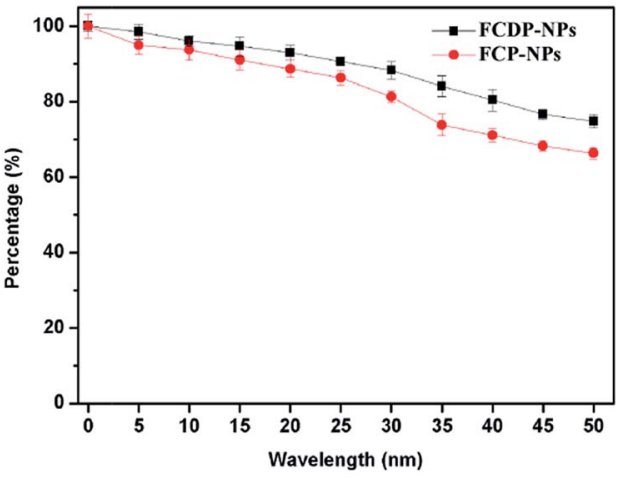

Fig. 5 The photobleaching plots based on the absorption of maximum at $705 \mathrm{~nm}$ in PBS.

conjugated $\pi$ bonds) could protect the PPA from being photobleached.

\subsection{Cell uptake}

A better therapeutic therapy needs efficient cellular uptaking for photosensitizer. In order to study the cell uptake of FCDP-NPs and efficient cellular location in HepG2 cells, the cells were treated with FCDP-NPs at various incubation times $(0.5 \mathrm{~h}, 1 \mathrm{~h}, 3$ h) were stained using DAPI, which is a fluorescence probe for cell nucleus. After staining the nucleus would display blue fluorescence, and PPa in the FCDP-NPs would emit red fluorescence, which could act as an indicator of the uptake behaviour of FCDP-NPs in cells. The cell uptaking experiments of $\mathrm{PPa}$ was also conducted. Fluorescence inverted microscopy was adopted to analyse the uptake behaviour. In our study, the concentration of FCDP-NPs was $50 \mu \mathrm{g} \mathrm{mL}{ }^{-1}$, and the concentration of PPa was $5 \mu \mathrm{g} \mathrm{mL} \mathrm{m}^{-1}$. The amounts of PPa in the two samples were consistent for reasonable comparison. Fig. 6 showed the experimental results, the spots with fluorescence stand for the cell nuclear stained by DAPI, the 'PPa' column and 'FCDP-NPs' column stand for the location of PPa with red fluorescence, and the 'Overlay' column stands for the merge of the DAPI column and the FCDP-NPs or PPa column. The images clearly showed that both FCDP-NPs and PPa can enter the cells quickly, and the fluorescence were observed to be increasing over the cell culture time for all samples. PPa and FCDP-NPs showed similar trend of uptaking for all time. But some remarkable differences of fluorescence intensity can be observed. The red fluorescence in PPa were a little stronger than that in FCDP-NPs after incubated with PSs for $1 \mathrm{~h}$, the reason for which may be that it need time for FCDP-NPs to release free PPa from the nanoparticles. As described earlier, about $46 \%$ of PPa would be resealed from FCDP-NPs after $1 \mathrm{~h}$, at this time, part of PPa was still encapsulated in the nanoparticles, so the fluorescence of FCDP-NPs groups were lower than that of the pure PPa. Moreover, the location of nanoparticles in cells could also be observed from the fluorescence signal. We have
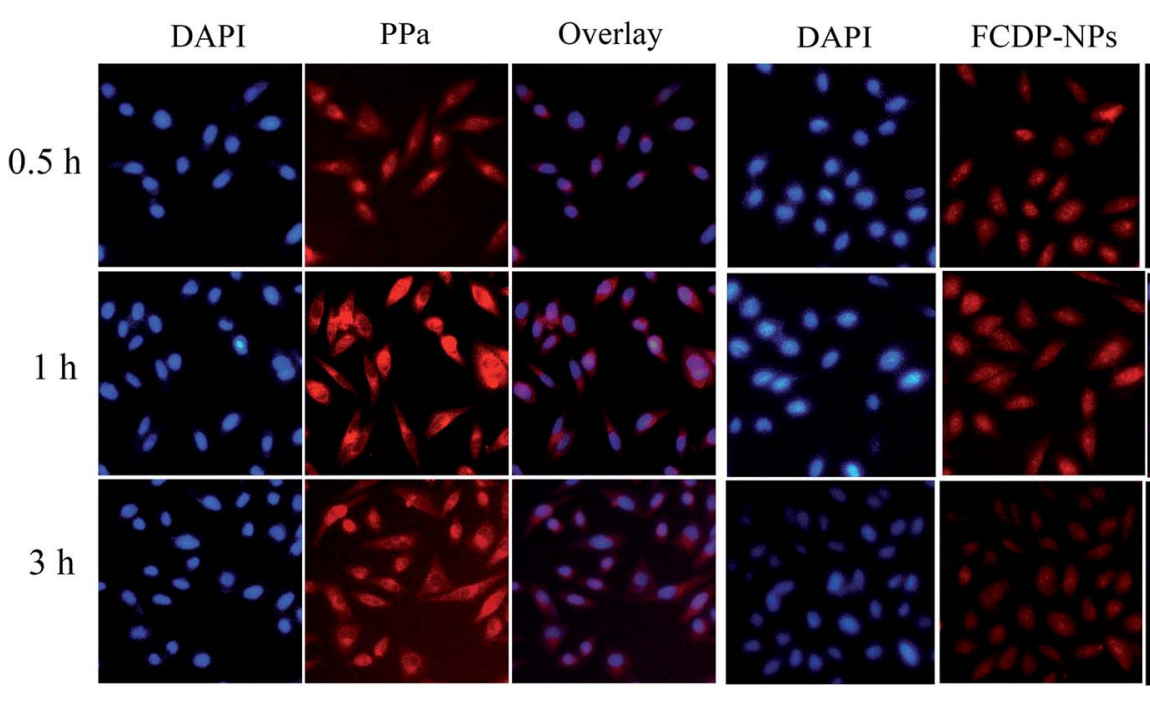

Overlay
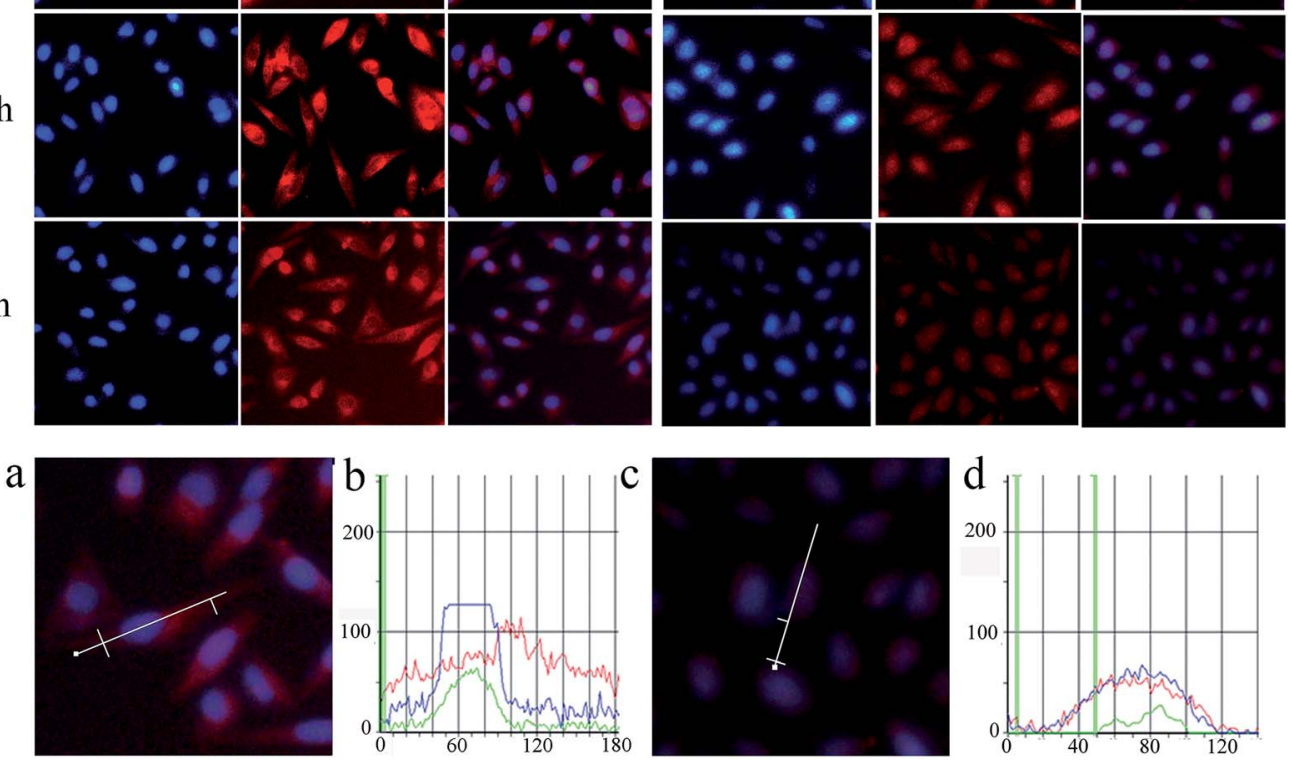

Fig. 6 Intracellular uptake of FCDP-NPs and PPa. Fluorescence inverted microscopic images of HepG2 cells incubated with FCDP-NPs and pure PPa at equivalent PPa concentration $\left(1 \mathrm{~mL}, 4 \mu \mathrm{g} \mathrm{mL}^{-1}\right)$ at $37^{\circ} \mathrm{C}$ for $0.5 \mathrm{~h}, 1 \mathrm{~h}, 3 \mathrm{~h}$ respectively. The nucleus was stained with DAPI showing blue fluorescence, and the red fluorescence was free PPa and PPa in FCDP-NPs. (a) Image of cells incubated with PPa for $3 \mathrm{~h}$ (b) the fluorescence distribution in image a (c) image of cells incubated with FCDP-NPs for $3 \mathrm{~h}$ (d) the fluorescence distribution in image (c). 

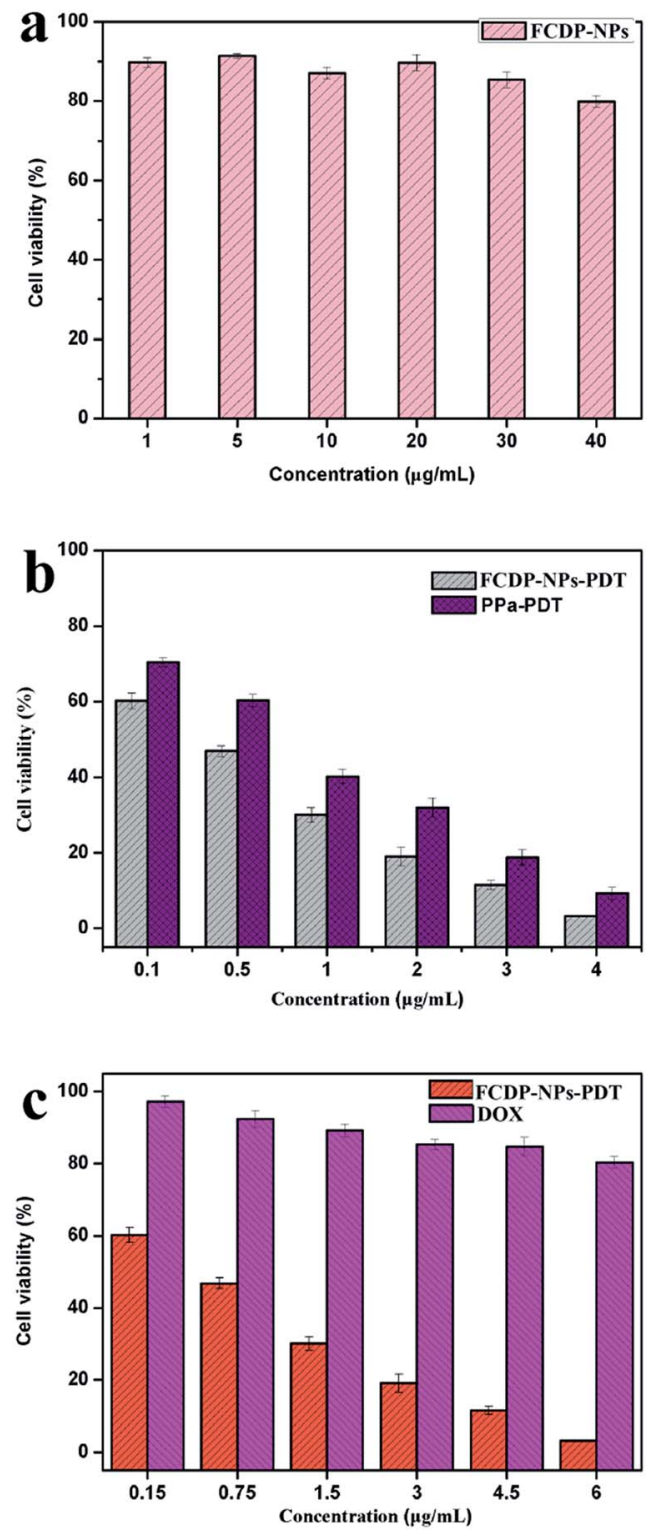

Fig. 7 The In vitro dark toxicity and PDT toxicity of PPa, DOX and FCDP-NPs on HepG2 cells incubated with different concentrations followed with or without irradiation for $5 \mathrm{~min}$. Cell viability was determined by MTT assay. Data are expressed as mean $\pm \mathrm{SD}(n=3)$. Statistical significant between groups were performed by $t$-test, and $p<0.05$ showed the difference was significant.

displayed the enlarged HepG2 cells after incubated with PPa and FCDP-NPs for $3 \mathrm{~h}$ in Fig. $6 \mathrm{a}$ and c respectively. Meanwhile the fluorescence distribution images of HepG2 cells were displayed in Fig. $6 \mathrm{~b}$ and $d$, in which the blue lines stand the fluorescence signal of DAPI, red lines stand for the fluorescence signal of $\mathrm{PPa}$, and the green lines stand for the background absorption. As showed in Fig. 6b, the blue fluorescence mainly distributed in cell nucleus, yet the red fluorescence distributed in a broad district suggesting that PPa was distributed throughout the cell. For FCDP-NPs shown in Fig. 6d, the blue and red fluorescence signal showed similar distribution. Due to DAPI was mainly located in cell nucleus, thus we can conclude that the FCDP-NPs was also mainly located in cell nucleus. This interesting phenomenon may be attributed to the target group folic acid and the existence of the DOX. It has been widely reported that DOX mainly acted in the site of cell nucleus. ${ }^{29,30}$ Therefore, the introduction of DOX to FCDP-NPs could improve the nucleus targetability to some degree.

\subsection{Dark toxicity and photodynamic activities toxicity}

In our previous report, pure PPa showed little dark cytotoxicity. However, due to the cytotoxicity of DOX, the cell dark toxicity of the FCDP-NPs should be evaluated for biomedical applications. Here, the dark toxicity and photodynamic toxicity were measured by MTT assay. As shown in Fig. 7a, the FCDP-NPs at the concentration ranging from 1 to $40 \mu \mathrm{g} \mathrm{mL}^{-1}$ did not cause any obvious cell toxicity effect compared with the negative control groups (cells treated with DMEM). For cell toxicity experiments, the tests were divided into three groups, that is, FCDP-NPs $\left(1,5,10,20,30\right.$ and $\left.40 \mu \mathrm{g} \mathrm{mL}^{-1}\right)$ groups, pure DOX groups $\left(0.15,0.75,1.5,3,4.5\right.$, and $\left.6 \mu \mathrm{g} \mathrm{mL}{ }^{-1}\right)$ and pure $\mathrm{PPa}$ groups $\left(0.1,0.5,1,2,3\right.$ and $\left.4 \mu \mathrm{g} \mathrm{mL}{ }^{-1}\right)$. The concentrations of PPa were equal to that in FCDP-NPs, and the concentrations of DOX were equal to that in FCDP-NPs. The cell toxicity was shown in Fig. 7b, both FCDP-NPs and PPa groups showed a drug concentration-dependent cytotoxicity to HepG2 cells after 5 min irradiation, while FCDP-NPs remarkably led higher cell mortality rate compared with free $\mathrm{PPa}$, indicating that the PDT activity of FCDP-NPs has been effectively improved compared with free PPa. Meanwhile, at the concentration of 40 $\mu \mathrm{g} \mathrm{mL}{ }^{-1}$, FCDP-NPs caused $92 \%$ cell mortality rate as shown in Fig. 7c, DOX (whose concentration was $6 \mu \mathrm{g} \mathrm{mL} \mathrm{L}^{-1}$ in FCDP-NPs) only cause $20 \%$ cell mortality rate. Based on the above analysis, the FCDP-NPs presented higher cell toxicity than pure DOX and pure $\mathrm{PPa}$, and introduction of DOX could effectively improve the PDF effect, with little dark cytotoxicity.

\subsection{Morphology}

We also assess the cell morphological changes of HepG2 cells by FIM in bright field after FCDP-NPs $\left(20 \mu \mathrm{g} \mathrm{mL}{ }^{-1}\right)$ PDT treatment and subsequently incubation for $0 \mathrm{~h}, 3 \mathrm{~h}, 6 \mathrm{~h}, 12 \mathrm{~h}$ respectively. From Fig. 8a-d, it is clear that the cells treated with FCDP-NPs at the studied concentrations displayed remarkable morphological changes when compared with the control groups treated with PBS. With the increasing of time, the cells were damaged. These results corroborated with the cell toxicity, confirmed the excellent photodynamic activities of the FCDP NPs. In order to further investigate the cell morphology after PDT. Acridine orange (AO) and ethidium bromide (EB) double fluorescent staining were used, then cell imaging was analysed by fluorescent inverted microscope and shown in Fig. 8e-h. Generally speaking, after incubation with AO and EB dyes, the dyes can bind to nucleus DNA of normal cell and necrotic cell, showing yellow-green fluorescence and reddish-orange fluorescence, respectively. Specially, the nucleus of early apoptotic cells would exhibit yellow-green fluorescence and appeared karyopyknosis; late apoptotic cell nucleus would show concentrated and asymmetrical reddish-orange fluorescence and appeared 

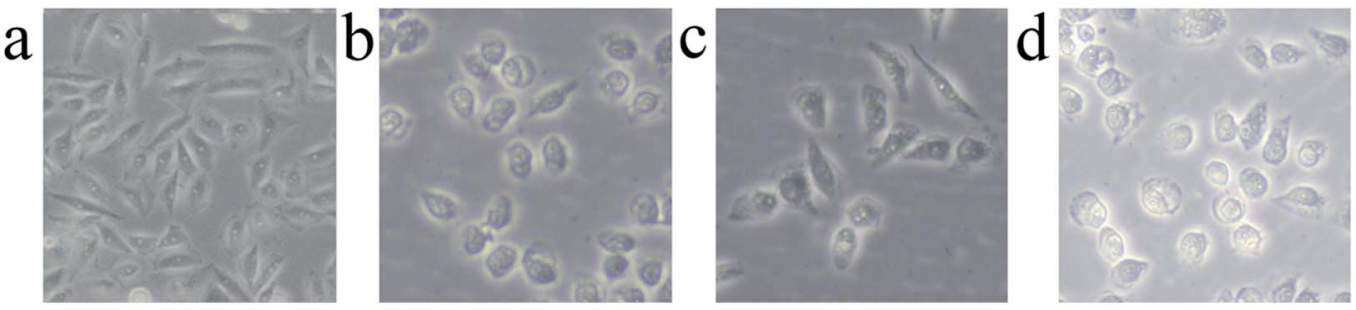

e
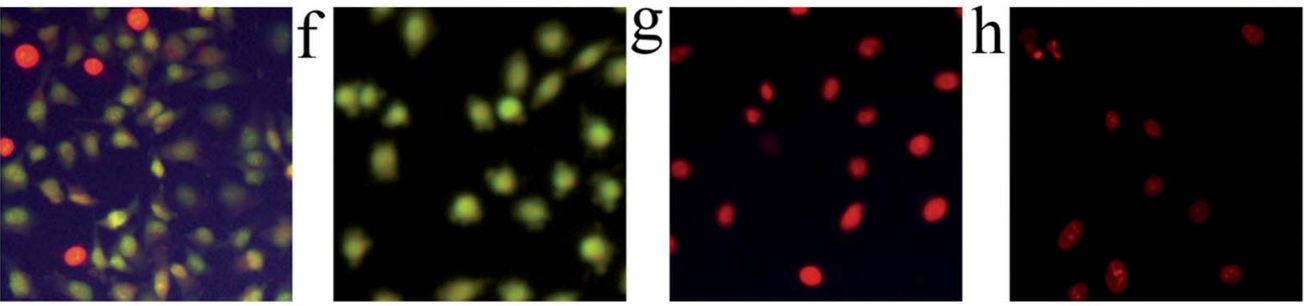

Fig. 8 Morphological changes of HepG2 cells incubated with FCDP-NPs (20 $\mu \mathrm{g} \mathrm{mL}^{-1}$ ) after PDT treatment $0 \mathrm{~h} \mathrm{(a),} 3 \mathrm{~h} \mathrm{(b),} 6 \mathrm{~h}$ (c), $12 \mathrm{~h} \mathrm{(d)} \mathrm{in} \mathrm{bright}$ field, respectively. FCDP-NPs induced damage and apoptotic death on HepG2 cells. Acridine orange (AO) and ethidium bromide (EB) double fluorescent staining were utilized as nuclear DNA marker to further observe the nuclear changes after FCDP-NPs PDT treatment. HepG2 cells were not treated (e) or treated $3 \mathrm{~h}(\mathrm{f}), 6 \mathrm{~h}(\mathrm{~g}), 12 \mathrm{~h}(\mathrm{~h})$ with FCDP-NPs with light irradiation for $5 \mathrm{~min}$, and then monitored by fluorescence inverted microscopic.

karyopyknosis as well; necrotic cells would show increased nucleus in volume and exhibit uneven reddish-orange fluorescence at their periphery. Based on the above investigation, the cell and nucleus morphological changes after FCDP-NPs treatment clearly indicated that FCDP-NPs had a higher PDT activity to induce damage and apoptotic cell death in $\mathrm{HepG}_{2}$ cells, which were also in good agreement of the significantly improved PDT efficiency in in vitro PDT testing.

\subsection{Type I and Type II mechanism during PDT progress}

The triplet state photosensitizer can directly interact with a substrate, and then passing an electron to nearby tissue

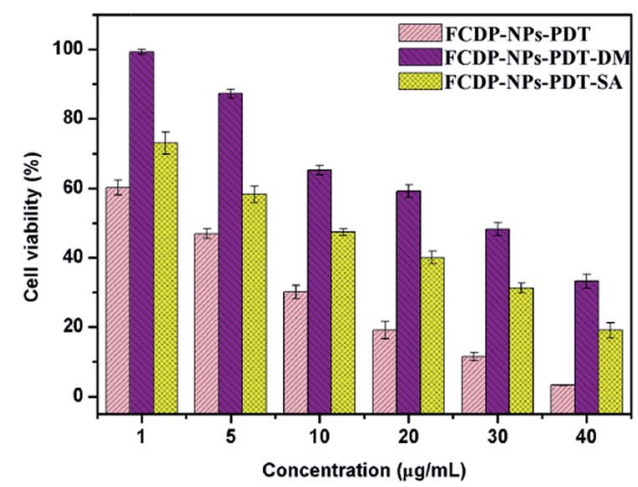

Fig. 9 The effects of different ROS (Type I and Type II photodynamic reaction) on HepG2 cells after PDT for $24 \mathrm{~h}$. FCDP-NPs-PDT group: different concentrations of FCDP-NPs $\left(1,5,10,20,30\right.$ and $\left.40 \mu \mathrm{g} \mathrm{mL}^{-1}\right)$ and exposed to light; FCDP-NPs-PDT-SA group: with FCDP-NPs and SA (singlet oxygen quencher, $20 \mathrm{mM}$ ) and exposed to light. FCDPNPs-PDT-DM group: with FCDP-NPs and DM (a hydroxyl radical quencher, $40 \mathrm{mM}$ ) and exposed to light. Cell viability was determined by MTT. Data represent mean \pm SD $(n=3)$. The significant difference between two groups was determined by $P$ values, which were calculated by student's $t$-test $(p<0.05)$. oxygen, producing oxygen centred radicals such as hydroxyl radicals (HR), superoxide anion as well as hydrogen peroxide (Type I PDT). Alternatively, the excitation energy can be directly transferred to nearby tissue oxygen to form ${ }^{1} \mathrm{O}_{2}$ (Type II PDT). The above ROS has a strong activity to induce tissue damage. In order to visualize the photochemical mechanisms of PDT, sodium azide (SA) and D-mannitol (DM), which has of relative specificity to ${ }^{1} \mathrm{O}_{2}$ and hydroxyl radicals (HR) respectively, were used to quench corresponding ROS of Type II and Type I originated from photodynamic reaction, and meanwhile confirm the two photodynamic types. ${ }^{35,36}$ The result were shown in Fig. 9. After adding quencher SA and DM into cells incubated with various concentration of FCDP-NPs, the cell viability of FCDPNPs-PDT-SA groups and FCDP-NPs-PDT-DM groups were significantly higher than that of FCDP-NPs-PDT groups, indicating that the $\operatorname{ROS}\left({ }^{1} \mathrm{O}_{2}\right.$ and hydroxyl radicals) generated from FCDP-NPs during PDT reaction have been quenched effectively. From the results, the Type I and Type II occurred simultaneously in this PDT process. Besides, the cell viability of FCDPNPs-PDT-DM groups was obviously higher than that of FCDPNPs-PDT-SA groups, indicating that Type I significantly greater effect on photodynamic effects than Type II.

\section{Experimental}

\subsection{Materials}

Chitosan $\left(M_{\mathrm{w}}>100 \mathrm{kDa}\right)$, tripolyphosphate (TPP), dicyclohexylcarbodiimide (DCC), doxorubicin and $N$-hydroxysuccinimide (NHS) were all purchased from Sigma. Pyropheophorbide acid was prepared according to the previous report. Dulbecco's Modified Eagle Medium (DMEM), dimethyl sulfoxide (DMSO), phosphate buffered saline (PBS), trypsin, 4',6-diamidino-2phenylindole (DAPI), 3-(4,5-dimethyl-2-thiazolyl)-2,5-diphenyl2- $H$-tetrazolium bromide (MTT), D-mannitol (DM), sodium azide (SA), 1,3-diphenylisobenzofuran (DPBF), acridine orange 
(AO) and ethidium bromide (EB) were purchased from sigma, and other reagent were of analytical grade and used without any purification. Deionized water with a resistivity of $18.2 \mathrm{M} \mathrm{cm}$ was obtained from a Milli-Q Gnadient System and used in all experiments. Human hepatoma cell line (HepG2) was obtained from ATCC.

\subsection{Synthesis of folate-chitosan conjugated with doxorubicin and pyropheophorbide acid nanoparticles (FCDP-NPs)}

The folic acid conjugated chitosan was prepared according to the previous reports. ${ }^{31,37,38}$ Briefly, for the synthesis of folic acid conjugated chitosan, at first, $300 \mathrm{mg}$ folic acid was dissolved in $10 \mathrm{~mL}$ DMSO, then $93 \mathrm{mg}$ dicyclohexylcarbodiimide (DCC), $77 \mathrm{mg} N$-hydroxysuccinimide (NHS) and $0.5 \mathrm{~mL}$ triethylamine were added, $30{ }^{\circ} \mathrm{C}$ stirring overnight. Flitted to remove the byproducts dicyclohexyl urea, then mixed by driping into cold anhydrous diethyl ether containing $30 \%$ acetone, finally got yellow precipitate, filtered, anhydrous diethyl ether washing several times after the vacuum drying, got NHS-ester of folic acid. Second, a DMSO solution of NHS-ester of folic acid was prepared and stirred at room temperature until the NHS-ester of folic acid was well dissolved, then added to a solution of chitosan in acetate buffer $(\mathrm{PH}=5.5)$, the mixture were stirred at room temperature in the dark for $16 \mathrm{~h}$. Then it was brought to $\mathrm{PH}=9$ by dropping $10 \mathrm{M} \mathrm{NaOH}$, filtrated to get the precipitation, wash by water for several times and resolved in $2 \%$ acetic acid aqueous solution, last separated by SepHadex G - 10 gel column ion, removed the free folic acid not reaction. The moving phase $2 \%$ acetic acid solution and the velocity was $1.5 \mathrm{~mL} \mathrm{~min}^{-1}$. A UV-visible spectrophotometer (UV-2000 SHIMADZU, Japan) was used to monitor the cleaning process at $363 \mathrm{~nm}$, collected the first effluent peak and freeze drying reserve to get the folate chitosan. Next a solution of the obtained folate chitosan was prepared in the $3 \mathrm{~mL} 2 \%$ acetic acid aqueous solution to get a final concentration of $2 \mathrm{mg} \mathrm{mL}{ }^{-1}$, $300 \mu \mathrm{g}$ doxorubicin and $300 \mu \mathrm{g}$ pyropheophorbide acid were added into the solution, it was brought to $\mathrm{PH}=5.5$ by dropping $10 \mathrm{M} \mathrm{NaOH}$, then stirred at room in the dark for $24 \mathrm{~h}$ to get folate chitosan conjugated doxorubicin and pyropheophorbide acid (FCDP). Finally, the FCDP was prepared in the $1.5 \mathrm{~mL} 2 \%$ acetic acid aqueous solution to get a final concentration of $4 \mathrm{mg} \mathrm{mL}{ }^{-1}$, then it was brought to $\mathrm{PH}=5$ by dropping $10 \mathrm{M}$ $\mathrm{NaOH}$, after that, $0.5 \mathrm{~mL} 2 \mathrm{mg} \mathrm{mL}^{-1}$ tripolyphosphate (TPP) was slowly dropped into the solution under magnetic stirring conditions, keeping stirring for $30 \mathrm{~min}$ to get the FCDP-NPs.

\subsection{Physicochemical characterization of FCDP-NPs}

UV-vis spectra was collected with a UV-2000 (SHIMADZU, Japan) at room temperature in a quartz cuvette with a path length of $1 \mathrm{~cm} .{ }^{39}$ The hydrodynamic size and zeta potential of composite was carried out with NanoBrook Zeta PALS Zeta Potential Analyzer (Brookhaven) at room temperature in water, the samples were diluted by ultrapure water and the $\mathrm{pH}$ value and concentration of the NPs dispersion were fixed before measurement. The shape and size of the FCDP-NPs were observed by a Tecnai G2 F20S-TWIN transmission electron microscope (TEM FEI, America) operating at $200 \mathrm{kV}$. TEM grids were prepared by depositing a drop of the diluted nanoparticle suspension on a carbon-coated copper support films and drying the grids under vacuum for $2 \mathrm{~h} .{ }^{40}$ The stabilities of FCDP-NPs in PBS $(\mathrm{PH}=5,7,9)$, were studied by an ultraviolet visible spectrophotometer (UV-2000, SHIMADZU, Japan). All the measurements were carried out at room temperature in a quartz cuvette with a path length of $1 \mathrm{~cm}$. The same concentration of FCDPNPs was dissolved in $3 \mathrm{~mL}$ PBS $(\mathrm{PH}=5,7,9)$ to got a finally concentration of $1 \times 10^{-4} \mathrm{M}$ respectively, then stored at $4{ }^{\circ} \mathrm{C}$ for different times. Then the absorbance at $705 \mathrm{~nm}$ was monitored at various time points. The loading capacity of FCDP-NPs was determined by the separation of nanoparticles from the water medium containing non-associated doxorubicin and pyropheophorbide acid by ultracentrifugation at $15000 \mathrm{rpm}, 4^{\circ} \mathrm{C}$ for $40 \mathrm{~min}$. The absorbance of $490 \mathrm{~nm}$ (for doxorubicin) and $683 \mathrm{~nm}$ (for pyropheophorbide acid) were measured by UV-2000 spectrometry (SHIMADZU, Japan), using a calibration curve of doxorubicin and pyropheophorbide acid in water. ${ }^{\mathbf{4 1}}$ Loading capacity (LC) of the FCDP-NPs was calculated as follows: LC\% $=$ (total drug - free drug) $/($ NPs weight $) \times 100$. The drug release of PPa was studied in DMEM cell culture medium, in brief, $2 \mathrm{mg}$ FCDP-NPs was dispersed in $3 \mathrm{~mL}$ DMEM cell culture medium at $37{ }^{\circ} \mathrm{C}$. At varying time points, the medium were measured by UV-vis spectra. Following supernatant extraction, FCDP-NPs were discarded. Calibration curves were made with the incubation medium, and all the experiments were performed three times, and the results were depressed as mean $\pm \mathrm{SD}$.

\subsection{Singlet oxygen quantum yield}

The singlet oxygen quantum yield of FCDP-NPs, FCP-NPs and PPa after light irradiation were measured by the singlet oxygen induced bleaching of 1,3-diphenylisobenzofuran (DPBF) using methylene blue as the reference compound. ${ }^{\mathbf{4 2 , 4 3}}$ In a typical experiment, $20 \mu \mathrm{L}$ of solutions of pure PPa, FCP-NPs and FCDP-NPs (containing the same PPa concentration of $2.8 \times$ $10^{-5} \mathrm{M}$ ) in DMF respectively, and then added into $3 \mathrm{~mL}$ of a stock solution of DPBF $\left(6 \times 10^{-5} \mathrm{M}\right)$ in DMF which had been transferred to a sealed quartz cuvette. Then irradiation by a calibrated visible light $675 \pm 10 \mathrm{~nm}\left(10 \mathrm{~J} \mathrm{~cm}^{-2}\right.$ NBET HS-UV300), the absorbance of the solution at $415 \mathrm{~nm}$ was measured every $10 \mathrm{~s}$ for a $110 \mathrm{~s}$ period with an UV-spectrophotometer (UV 2000, SHIMADZU, Japan). The singlet oxygen quantum yield $\left(\Phi_{\Delta}\right)$ was calculated using following equations:

$$
\begin{gathered}
\Phi_{\Delta}(\mathrm{S})=\Phi_{\Delta}(\mathrm{R}) k^{\mathrm{S}} I_{\mathrm{aT}}(\mathrm{R}) / k^{\mathrm{R}} I_{\mathrm{aT}}(\mathrm{S}) \\
I_{\mathrm{a}}=I_{0}\left(1-\mathrm{e}^{-2.3 A}\right)
\end{gathered}
$$

$\Phi_{\Delta}$ was calculated on the basis of eqn (1) and (2). Superscript S and $\mathrm{R}$ represent the sample and reference compound, respectively. Where $k$ is a slope of the liner model. The first-order linear least squares model to get the singlet oxygen quantum yield of PPa, FCP-NPs and FCDP-NPs in DMF, obtained by plotting $-\ln \left([\mathrm{DPBF}]_{t} /[\mathrm{DPBF}]_{0}\right)$ as a function of the irradiation 
time $t$, where $[\mathrm{DPBF}]_{t}$ and $[\mathrm{DPBF}]_{0}$ represent the absorbance of DPBF at time $t$ and at time 0 , respectively. $I_{\mathrm{aT}}$ is defined as the total amount of light absorbed by photosensitizers. $A$ and $I_{0}$ stands the corresponding absorbance at irradiation wavelength and transmittance of filter at given wavelength, respectively. The rate constant was then converted into singlet oxygen quantum yield by comparison with the similar rate of methylene blue mediated photo oxidation to DPBF. Methylene blue $\left(\Phi_{\Delta}=49.1 \%\right)$ in DMF was used as the reference compound.

\subsection{Photobleaching of FCDP NPs}

For the photobleaching experiments, ${ }^{44,45}$ FCDP-NPs was dissolved in PBS to get a final concentration of $5 \times 10^{-4} \mathrm{M}$, and transfer the solution to $1 \times 1 \mathrm{~cm}$ glass cuvettes, then irradiation with a calibrated visible light every $5 \min (675 \pm 10 \mathrm{~nm}$, $10 \mathrm{~J} \mathrm{~cm}^{-2}$ NBET HS-UV300), the absorption at $705 \mathrm{~nm}$ were recorded using a UV-spectrophotometer at interval of $5 \mathrm{~min}$ before irradiation and during the irradiation, after irradiation for $0 \mathrm{~min}, 5 \mathrm{~min}, 10 \mathrm{~min}, 15 \mathrm{~min}, 20 \mathrm{~min}, 25 \mathrm{~min}, 30 \mathrm{~min}$, $35 \mathrm{~min}, 40 \mathrm{~min}, 45 \mathrm{~min}, 50 \mathrm{~min}$, the absorptions at $705 \mathrm{~nm}$ had been tested respectively. All the experiments were carried out at room temperature and in dark. The experiments were performed three times; the results were showed as mean $\pm \mathrm{SD}$.

\subsection{Cell culture}

Human hepatica cell line (HepG2) were cultured in Dulbecco's modified Eagle's medium (DMEM medium) supplemented with $10 \% \mathrm{FBS}, 100$ units per $\mathrm{mL}$ of penicillin and 100 units per $\mathrm{mL}$ of streptomycin at $37^{\circ} \mathrm{C}$ in a humid $5 \% \mathrm{CO}_{2}$ incubator. Cells were grown in $75 \mathrm{~cm}^{2}$ culture flacks with $7 \mathrm{~mL}$ of medium that was changed every second days until a sufficient number of cells were obtained. Cells were than washed three times with PBS and incubated with trypsin-EDTA solution (0.25\% trypsin, $1 \mathrm{mM}$ EDTA) for $2 \mathrm{~min}$ at $37{ }^{\circ} \mathrm{C}$ to detach them from the flask. The cells were then suspended in medium in preparation for reseeding. Cells density was determined by counting cells using a haemocytometer with $0.9 \mathrm{~mm}^{3}$ counting chamber. ${ }^{46}$ And cell viability were determined by MTT (3-(4,5-dimethylthiazol-2-yl)2,5-diphenyltetrazolium bromide) assay and a Biotek ELx800 absorbance microplate reader was used in MTT assay.

\subsection{Dark toxicity assay}

The dark toxicity was tested by MTT colorimetric assay ${ }^{47}$ in brief, HepG2 cells were seeded into 96-well plates with $100 \mu \mathrm{L}$ fresh medium at a density of $1 \times 10^{4}$ cells per well. After incubation for $12 \mathrm{~h}$ to bring the cells to confluence, the medium was replaced with $200 \mu \mathrm{L}$ fresh medium containing FCDP-NPs with different final concentrations $\left(1,5,10,20,30\right.$, and $40 \mu \mathrm{g} \mathrm{mL}{ }^{-1}$, respectively) and the cells were incubated for $24 \mathrm{~h}$ at $37^{\circ} \mathrm{C}$ and $5 \% \mathrm{CO}_{2}$. Thereafter, MTT solution $\left(20 \mu \mathrm{L}, 5 \mathrm{mg} \mathrm{mL}^{-1}\right.$ in PBS buffer) was added into each well and the cells were incubated for another $4 \mathrm{~h}$. The assays were carried out according to the manufacturer's instruction. The absorbance at $570 \mathrm{~nm}$ of each well was measured using a Biotek ELx800 absorbance microplate reader. Cell viability (\%) was then calculated by the equation:

$$
\text { Cell viability }(\%)=\left(A_{\mathrm{s}}-A_{\mathrm{b}}\right) /\left(A_{\mathrm{c}}-A_{\mathrm{b}}\right) \times 100 \%
$$

where $A_{\mathrm{s}}$ is the average absorbance of the wells treated with various concentrations of FCSP-NPs, $A_{\mathrm{c}}$ is the average absorbance of the wells treated with DMEM containing $10 \%$ fetal bovine serum (FBS), and $A_{\mathrm{b}}$ is the average absorbance of the wells treated with PBS buffer. For each samples mean and standard deviation of five parallel wells were recorded and the experiments were performed three times.

\subsection{Cell uptake}

Fluorescence Inverted Microscope (FIM) was used to investigated the cell uptake on HepG2 cell. HepG2 cells $\left(1 \times 10^{6}\right.$ cells per well) were seeded in 6-well plates and incubated overnight at $37^{\circ} \mathrm{C}$ in a humidified $\mathrm{CO}_{2}$ atmosphere. After being rinsed with PBS, the cells were incubated with $1 \mathrm{~mL}, 50 \mu \mathrm{g} \mathrm{mL} \mathrm{m}^{-1}$ of FCDPNPs or pure $5 \mu \mathrm{g} \mathrm{mL} L^{-1} \mathrm{PPa}$ for $0.5 \mathrm{~h}, 1 \mathrm{~h}$ and $3 \mathrm{~h}$ respectively at $37^{\circ} \mathrm{C}$ in the dark under the same conditions. For observed, the cells were rinsed with PBS, then fixed with glutaraldehyde for $10 \mathrm{~min}$ and stained with DAPI $\left(1 \mu \mathrm{g} \mathrm{mL} \mathrm{m}^{-1}\right.$ in PBS $)$ for $10 \mathrm{~min}$, observed via a Fluorescence Inverted Microscope (Leica DM IL LED, Leica Microsystems, Germany). ${ }^{47,48}$

\subsection{Cytotoxicity and cell morphology observation}

MTT assay was used to quantify the viability of the cells after treated with FCDP-NPs, pure DOX and pure PPa at different concentration. Briefly, HepG2 cells were seeded into a 96-well plate at an initial density of $1 \times 10^{4}$ cells per well in $100 \mu \mathrm{L}$ DMEM medium. After overnight incubation to bring the cell to confluence, the medium was replaced with $100 \mu \mathrm{L}$ fresh medium containing pure PBS buffer (set as blank), FCDP-NPs $\left(1,5,10,20,30\right.$ and $\left.40 \mu \mathrm{g} \mathrm{mL}^{-1}\right)$, pure $\operatorname{DOX}(0.15,0.75,1.5,3,4.5$ and $\left.6 \mu \mathrm{g} \mathrm{mL} \mathrm{m}^{-1}\right)$, pure PPa $\left(0.1,0.5,1,2,3\right.$ and $\left.4 \mu \mathrm{g} \mathrm{mL} \mathrm{m}^{-1}\right)$ were added into the 96 cell plates respectively. After $4 \mathrm{~h}$ incubation, exposed the cells to visible light for $5 \min (675 \pm 10 \mathrm{~nm}$, $10 \mathrm{~J} \mathrm{~cm}^{-2}$ NBET HS-UV300), incubation at $37^{\circ} \mathrm{C}$ and $5 \% \mathrm{CO}_{2}$ for another $24 \mathrm{~h}$. Then $20 \mu \mathrm{L}$ MTT $\left(0.5 \mathrm{mg} \mathrm{mL}^{-1}\right.$ in PBS buffer) was added to each well to detect the metabolically active cells. After further incubation for $4 \mathrm{~h}$ in an incubator at $37^{\circ} \mathrm{C}, 150 \mu \mathrm{L}$ DMSO was added to each well to replace the culture medium and dissolve the insoluble formazan crystals. The assays were carried out according to the manufacturer's instructions and the absorbance of each well was measured using a (a Biotek ELx800 absorbance microplate reader) at $570 \mathrm{~nm}$. The results were shown mean $\pm \mathrm{SD}$, all the experiments were performed three times. For morphology observation, HepG2 cells were seeded into a 6-well plate at an initial density of $1 \times 10^{6}$ cells per well in $1000 \mu \mathrm{L}$ DMEM medium. After overnight incubation to bring the cell to confluence, the medium was replaced with $1000 \mu \mathrm{L}$ FCDP-NPs $\left(20 \mu \mathrm{g} \mathrm{mL} \mathrm{m}^{-1}\right)$, after $4 \mathrm{~h}$, the cells were exposed under light $\left(675 \pm 10 \mathrm{~nm}, 10 \mathrm{~J} \mathrm{~cm}^{-2}\right.$ NBET HS-UV300), then continue incubated for $0 \mathrm{~h}, 3 \mathrm{~h}, 6 \mathrm{~h}, 12 \mathrm{~h}$ respectively, then stained by acridine orange ( $\mathrm{AO}, 100 \mu \mathrm{g} \mathrm{mL}^{-1}$ ) and ethidium bromide (EB, $100 \mu \mathrm{g} \mathrm{mL}{ }^{-1}$ ), finally, the cells morphology were observed by a Fluorescence Inverted Microscope (FIM, Leica DM IL LED, Leica Microsystems, Germany). 


\subsection{Type I and Type II mechanism during PDT progress}

Type I and Type II mechanism of PDT on HepG2 cells was investigated by MTT colorimetric assay and cell viability were monitored. The quenchers sodium azide (SA, Sigma-Aldrich) and Dmannitol (DM, Sigma-Aldrich), which have relative specificity for singlet oxygen $\left({ }^{1} \mathrm{O}_{2}\right)$ and hydroxyl radicals respectively, ${ }^{49}$ can quench the corresponding ROS generated from photodynamic reaction. The experiments were divided into three groups: FCDPNPs photo-toxicity experiment groups, FCDP-NPs-SA phototoxicity experiment groups, FCDP-NPs-DM photo-toxicity experiment groups. HepG2 cells were seeded into 96-well plates at a density of $1 \times 10^{4}$ cells per well in DMEM and incubated for $24 \mathrm{~h}$. Then, the medium were replaced by $100 \mu \mathrm{L}$ of different concentrations of FCDP-NPs in all of the three experiment groups. The final concentrations of FCDP-NPs were 1, 5, 10, 20, 30, and $40 \mu \mathrm{g}$ $\mathrm{mL}^{-1}$. In addition, added $20 \mu \mathrm{L}$ SA $(20 \mu \mathrm{M})$ to each well of the FCDP-NPs-SA photo-toxicity experiment groups and added $20 \mu \mathrm{L}$ DM $(40 \mu \mathrm{M})$ to each well of the FCDP-NPs-DM photo-toxicity experiment groups. Then, the three groups were incubated for $4 \mathrm{~h}$ followed by exposure to visible light $\left(675 \pm 10 \mathrm{~nm}, 10 \mathrm{~J} \mathrm{~cm}^{-2}\right.$ NBET HS-UV300) for $5 \mathrm{~min}$, and then cultured in the dark for an additional $24 \mathrm{~h}$ in DMEM media at $37{ }^{\circ} \mathrm{C}$ under $5 \% \mathrm{CO}_{2}$ conditions. Cell viability was determined by MTT assay. Each experiment was repeated three times, the results were described as mean $\pm \mathrm{SD}$.

\subsection{Statistical analysis}

Results were expressed as the mean \pm SD from three independent experiments, comparison between different groups were determined using T-text and significant differences were assumed at $P$ value $<0.05$. The dates were analysed using SPSS 19.0 software.

\section{Conclusions}

In summary, we have successfully prepared multifunctional folate chitosan conjugated DOX and PPa nanoparticles (FCDP-NPs). FCDP-NPs showed good chemical stability in PBS $(\mathrm{pH}=5,7,9)$, and excellent photo-stability in PBS $(\mathrm{pH}=7.4)$, and high singlet oxygen yield (64\%). FCDP-NPs possess tumor targeting due to the introduction of folic acid, and remarkable anti-tumor activity against HepG2 cells because of DOX. Meanwhile, through cell uptaking experiments, we have found that DOX could improve the nuclear targeting capability of FCDP-NPs to some degree. FCDP-NPs showed higher cell toxicity after irradiation by light, but low dark toxicity without irradiation despite the introduction of DOX. The morphological changes of HepG2 cells further indicated that FCDP-NPs can induce damage and apoptotic cell death. Meanwhile, we confirmed that Type I and Type II photodynamic reactions occurred simultaneously during PDT process, and Type I reaction (the generation of hydroxyl radicals) plays a predominant role. All the results showed the FCDP-NPs would have great potential in applications in clinical patients with tumour cancer.

\section{Conflicts of interest}

There are no conflicts to declare.

\section{Acknowledgements}

Financial support of this research was provided by the National Natural Science Foundation of China (No. 21272048), the Natural Science Youth Foundation of Heilongjiang Province (No. QC2016011) and the Scientific Research Fund of Heilongjiang Provincial Education Department (No. 12531194, 12541234) and the Graduate Innovation Foundation of Harbin Normal University.

\section{References}

1 X.-H. Zhang, L.-J. Zhang, J.-J. Sun, Y.-J. Yan, L.-X. Zhang, N. Chen and Z.-L. Chen, Biomed. Pharmacother., 2016, 81, 265-272.

2 Z. Meng, B. Shan, L. Zhang, G.-Y. Han, M.-H. Liu, N.-Y. Jia, Z.-Y. Miao, W.-N. Zhang, C.-Q. Sheng and J.-Z. Yao, Chin. Chem. Lett., 2016, 27, 623-626.

3 G.-J. Cao, R.-X. Rong, Y.-N. Wang, Q. Xu, K.-R. Wang and X.-L. Li, Dyes Pigm., 2017, 136, 569-576.

4 D. Zhang, M. Wu, Y. Zeng, L. Wu, Q. Wang, X. Han, X. Liu and J. Liu, ACS Appl. Mater. Interfaces, 2015, 7, 8176-8187.

5 H. Ding, H. Yu, Y. Dong, R. Tian, G. Huang, D. A. Boothman, B. D. Sumer and J. Gao, J. Controlled Release, 2011, 156, 276280.

6 A. Roby, S. Erdogan and V. P. Torchilin, Eur. J. Pharm. Biopharm., 2006, 62, 235-240.

7 G. Kirdaite, N. Lange, N. Busso, H. V. D. Bergh, P. Kucera and A. So, Arthritis Rheum., 2002, 46, 1371-1378.

8 A. Mateašík, M. Trnka, K. Kajo, M. Vallová and B. Čunderlíková, J. Photochem. Photobiol., B, 2016, 166, 94.

9 M. Korbelik, Lasers Surg. Med., 2006, 38, 500-508.

10 Y. G. Qiang, C. M. N. Yow and Z. Huang, Med. Res. Rev., 2008, 28, 632-644.

11 T. C. Zhu and J. C. Finlay, Med. Phys., 2008, 35, 3127.

12 A. Kamkaew, S. H. Lim, B. L. Hong, L. V. Kiew, L. Y. Chung and K. Burgess, Chem. Soc. Rev., 2013, 42, 77-88.

13 D. A. Bellnier, W. R. Greco, G. M. Loewen, H. Nava, A. R. Oseroff, R. K. Pandey, T. Tsuchida and T. J. Dougherty, Cancer Res., 2003, 63, 1806-1813.

14 S. J. Mora, M. P. Cormick, M. E. Milanesio and E. N. Durantini, Dyes Pigm., 2010, 87, 234-240.

15 P. D. Senter and J. Kopecek, Mol. Pharm., 2004, 1, 395.

16 Y. Kato, H. Onishi and Y. Machida, Biomaterials, 2004, 25, 907-915.

17 M. S. Islam, P. Haque, T. U. Rashid, M. N. Khan, A. K. Mallik, M. N. Khan, M. Khan and M. M. Rahman, J. Mater. Sci.: Mater. Med., 2017, 28, 55.

18 Y. S. Lin, R. Radzi, M. Morimoto, H. Saimoto, Y. Okamoto and S. Minami, J. Biomater. Sci., Polym. Ed., 2012, 23, 1401-1420.

19 S. M. Reza, R. M. Tabatabaie, A. Maharramov and R. M. Ali, Int. J. Biol. Macromol., 2011, 49, 1059-1065.

20 Y. Wu, W. Yang, C. Wang, J. Hu and S. Fu, Int. J. Pharm., 2005, 295, 235-245.

21 G. Storm, S. O. Belliot, T. Daemen and D. D. Lasic, Adv. Drug Delivery Rev., 1995, 17, 31-48. 
22 M. R. Saboktakin, R. M. Tabatabaie, A. Maharramov and M. A. Ramazanov, Int. J. Biol. Macromol., 2011, 49, 10591065.

23 A. C. Antony, Annu. Rev. Nutr., 1996, 16, 501.

24 H. Wang, L. Zheng, C. Peng, M. Shen, X. Shi and G. Zhang, Biomaterials, 2013, 34, 470-480.

25 W. Qi, A. Wang, Y. Yang, M. Du, M. N. Bouchu, P. Boullanger and J. Li, J. Mater. Chem., 2010, 20, 2121-2127.

26 C. H. M. Ng and A. L. Jackman, Potential for $\alpha$-Folate ReceptorTargeted Treatment for Ovarian Cancer, Springer, New York, 2011.

27 X. C. Qin, Z. Y. Guo, Z. M. Liu, W. Zhang, M. M. Wan and B. W. Yang, J. Photochem. Photobiol., B, 2013, 120, 156-162.

28 H. Azaïs, P. Foucher, A. Bassil, S. K. Bach, B. Leroux, J. B. Tylcz, C. Frochot, N. Betrouni, P. Collinet and S. Mordon, Photodiagn. Photodyn. Ther., 2017, 17, A10.

29 N. U. Khaliq, F. C. Sandra, D. Y. Park, J. Y. Lee, K. S. Oh, D. Kim, Y. Byun, I.-S. Kim, I. C. Kwon, S. Y. Kim and S. H. Yuk, Biomaterials, 2016, 101, 131-142.

30 N. Zhao, B. Wu, X. Hu and D. Xing, Biomaterials, 2017, 141, 40-49.

31 B. Stella, S. Arpicco, M. T. Peracchia, D. Desmaële, J. Hoebeke, M. Renoir, J. D'Angelo, L. Cattel and P. Couvreur, J. Pharm. Sci., 2000, 89, 1452-1464.

32 Z. Musil, P. Zimcik, M. Miletin, K. Kopecky, P. Petrik and J. Lenco, J. Photochem. Photobiol., A, 2007, 186, 316-322.

33 Y. Cheng, A. C. Samia, J. D. Meyers, I. Panagopoulos, B. Fei and C. Burda, J. Am. Chem. Soc., 2008, 130, 10643-10647.

34 L. Zhang, K. Yan, Y. Zhang, R. Huang, J. Bian, C. Zheng, H. Sun, Z. Chen, N. Sun and R. An, Proc. Natl. Acad. Sci., 2007, 104, 4606-4611.
35 S. F. Mujtaba, A. Dwivedi, N. Yadav, R. S. Ray and G. Singh, J. Hazard. Mater., 2013, 252-253, 258-271.

36 H. Li, X. Yi, K. Yuichiro, Z. Timur, T. Masamitsu and H. Michael, Lasers Surg. Med., 2012, 44, 490-499.

37 K. A. Janes, M. P. Fresneau, A. Marazuela, A. Fabra and M. a. J. Alonso, J. Controlled Release, 2001, 73, 255-267.

38 H. Jian, S. Duan, Y. Xia, Z. Qian, S. Zhou, Z. Zhang, X. Huang, H. Yong, S. Jing and C. Lai, Theranostics, 2016, 6, 752-761.

39 J. Li, Y. Hu, J. Yang, P. Wei, W. Sun, M. Shen, G. Zhang and X. Shi, Biomaterials, 2015, 38, 10-21.

40 J. Li, L. Zheng, H. Cai, W. Sun, M. Shen, G. Zhang and X. Shi, Biomaterials, 2013, 34, 8382-8392.

41 S. Mansouri, Y. Cuie, F. Winnik, Q. Shi, P. Lavigne, M. Benderdour, E. Beaumont and J. C. Fernandes, Biomaterials, 2006, 27, 2060-2065.

42 X. Chen, Z. Zhao, M. Jiang, D. Que, S. Shi and N. Zheng, New J. Chem., 2013, 37, 1782-1788.

43 B. Meesaragandla, D. Sarkar, V. N. K. B. Adusumalli and V. Mahalingam, New J. Chem., 2016, 40, 3080-3085.

44 A. Manuel, C. Pierre, M. O. Farine and M. Serge, Lasers Surg. Med., 2008, 40, 332-341.

45 J. Ann, F. Florian, K. Gesa, D. Phys, H. Stepp, R. Sroka, E. Rupert and W. Beyer, Lasers Surg. Med., 2013, 45, 225-234.

46 C. Sun, R. Sze and M. Zhang, J. Biomed. Mater. Res., Part A, 2006, 78, 550-557.

47 M. Ahir, S. Bhattacharya, S. Karmakar, A. Mukhopadhyay, S. Mukherjee, S. Ghosh, S. Chattopadhyay, P. Patra and A. Adhikary, Biomaterials, 2016, 76, 115-132.

48 P. Huang, L. Bao, C. Zhang, J. Lin, T. Luo, D. Yang, M. He, Z. Li, G. Gao and B. Gao, Biomaterials, 2011, 32, 9796-9809.

49 J. Cheng, G. Tan, W. Li, H. Zhang, X. Wu, Z. Wang and Y. Jin, New J. Chem., 2016, 40, 8522. 